\title{
Living Space for Lemurs
}

\author{
Richard Fitter
}

Madagascar has one of the most interesting and scientifically valuable faunas in the world, with many endemic species, notably the lemurs. But forest destruction here as elsewhere threatens its survival. In October 1970 IUCN held a conference in Tananarive to highlight the island's importance and to interest both government and people in conserving this unique wildlife. FPS was represented by the Hon. Secretary, who here describes the situation and reports several hopeful and encouraging aspects.

Madagascar has been evolving its own flora and fauna since the break-up of the great land-mass in the Mesozoic Era. More than 65 million years ago, it was split off from Asia and soon afterwards from Africa, as the general validation of the theory of Continental Drift now makes it respectable to recognise. A few fresh arrivals have come in by sea and air, but 86 per cent of the flora, and 66 per cent of the birds ( 95 per cent of the passerines) are endemic. Biologists now recognise a separate Malagasy zoo- and phyto-geographical region fully equivalent to the Ethiopian and Oriental Regions. During these millions of years adaptive radiation of such groups as the lemurs and the insectivore tenrecs has taken place on an almost continental scale. Apart from Australia with its marsupials, there is no better natural laboratory in the world in which to study evolution - the better known Galapagos Islands, with their Darwin's finches and marine iguanas, and Hawaiian islands with their honeycreepers, have histories numbered only in thousands of years. In the lemurs, moreover, recent behaviour studies using modern observational techniques, have revealed the most fascinating parallels with the monkeys, for instance between the social behaviour of the maki Lemur catta and the South American squirrel monkey Saimurus.

Besides its unexampled flora and fauna, several features make Madagascar unique as a habitat. It is a very largeisland, nearly 600,000 square kilometres, but is not on a continental shelf. It is tropical in character, and has a wide range of altitude and rainfall. On the other hand its comparatively few species are in striking contrast to other tropical areas-where the profusion of species is a well known phenomenon. This feature alone makes Madagascar a uniquely valuable natural laboratory. Added to the evolutionary aspects, it makes Madagascar the most scientifically important region of its size in the world.

There are therefore special reasons for desiring the preservation and conservation of habitats in Madagascar over and above those which apply in all countries. At present Madagascar has two national parks and a dozen forest, mountain and freshwater nature reserves. These are a good beginning, but all need to be enlarged, and in any case do not provide a home for by any means all the endemic species, or even all the threatened ones. Moreover one reserve at least has recently been 
descheduled. Several other areas such as the Sept Lacs, near Tulea, on the south-west coast and the Lac Ambereny, only known locality for Bernier's teal Anas bernieri, also need the protection of reserve status.

However large areas of forest still exist, especially on the east side of the island, which since trains of porters ceased to be available have become virtually inaccessible to naturalists, or anybody else. Here, as in a good many other still accessible areas, such as Perinet, on the railway between Tananarive and the east coast, lemurs can still quite readily be seen by those with the necessary patience and observational skill. It is more than likely that some of the forms of lemur now listed as endangered or even presumed extinct may, as with several Australian marsupials, be found to be more numerous than had been feared. The one exception is the aye-aye, sole surviving representative of the family Daubentoniidae and one of the strangest mammals in the world. This used to be found in the forests all up the east coast, but these are the forests which have been most heavily depleted, and only a few thousand hectares remain, about 1000 of them in a reserve. Details of the largely WWF-financed operation to translocate nine aye-ayes to the island of Nosy Mangabé off the north-east coast at Maroantsetra were given in ORYX for April 1967. This island already holds a native stock of lemurs Lemur fulvus-and an introduced one of ruffed lemurs $L$. variegatus. For some years past conservationists have been worried at the steady erosion of what remained of the natural and semi-natural habitats of Madagascar, as well as the endemic flora and fauna. Excessive felling of woodland and burning of grassland and scrub are the two chief causes. Fourteen out of thirty-three recent species, especially the slow-moving diurnal forms, were killed off in prehistoric times, largely by habitat destruction. Twenty-four surviving species and subspecies are listed in the Red Data Book of Endangered Mammals.

This was the background to IUCN's decision to persuade the Malagasy Government to hold an international conference on the rational utilisation and conservation of nature. The conference, organised by Jean Jacques Petter, of the Museum d'Histoire Naturelle in Paris, took place in the Malagasy capital Tananarive from October $7^{-1 I}$, and was attended by leading scientific conservationists from all over the world. The FPS was represented, and invited to address the conference, which the Society had been glad to aid in its preparatory stages with a small grant from the FPS/WWF Revolving Fund. The main aim of the conference was to stimulate interest in the government and people of Madagascar in their country's substantial riches of natural resources, to demonstrate the great scientific and economic value of these resources, and to promote their active conservation and rational use.

On the whole, however, whatever may have happened in the pastand much of the damage was done long before Madagascar swam into the ken of the western world-the situation today is by no means as hopeless as it seems in large parts of Asia and Latin America. The population (c. 6 million) is relatively small in an island of $587,000 \mathrm{sq} . \mathrm{km}$. There is a thriving Département des Eaux et Forêts, albeit starved of funds. There is the constant interest of a powerful and wealthy western 
power, symbolised by the tricolor that flies so often alongside the Malagasy flag-and France still wholly supports the University. There is, too, at least the dawning of a public consciousness of the need to conserve the national patrimony, to manage it rationally and not to squander it.

But the crux of the matter, as usual, is money. Who is to pay the very substantial sums that are needed if the scientific and economic potential of Madagascar's natural resources are to be conserved and managed for the general benefit? What is needed is easily listed: larger reserves and national parks, a well equipped cadre of wardens, more and better equipped research stations, and a chain of tourist lodges and rest houses to enable the substantial tourist potential to be realised.

In so far as direct economic returns can be expected, it is not unreasonable to expect the Malagasy Government, aided by France and the appropriate international agencies, to bear the costs. Already, for instance, an

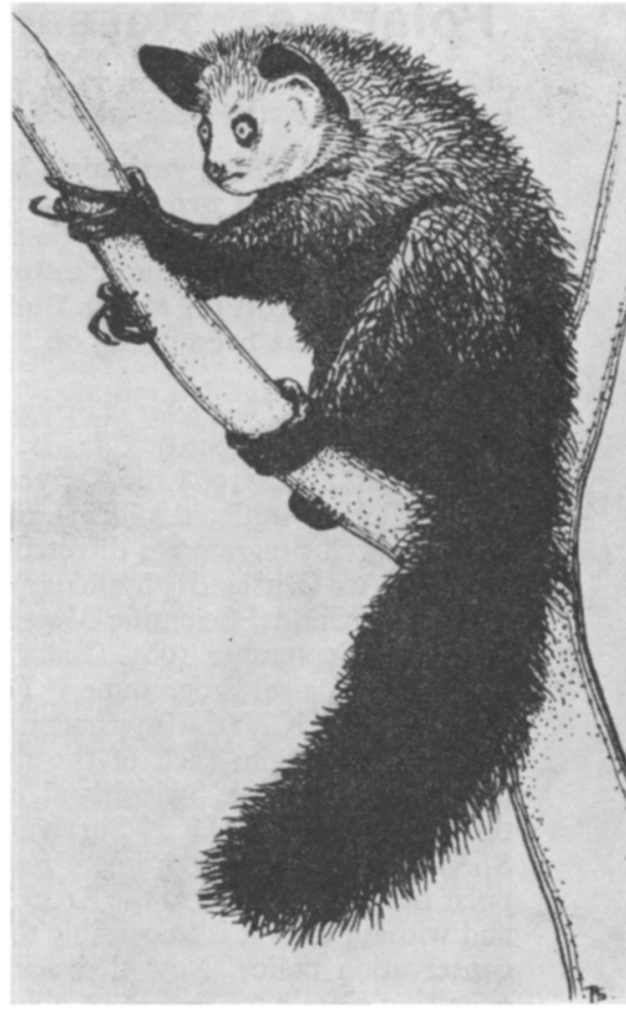

The aye-aye - Madagascar's rarest lemur Peter Scott

FAO project on wildlife resources is planned. However, in so far as what must be preserved is of international scientific interest, surely the world must not expect the local government to bear the whole burden. While one can expect wealthy countries such as the USA and Britain to preserve such international scientific treasures as Hawaii and Aldabra for the general benefit, the whole international community should be prepared to help Ecuador with the Galapagos, Ethiopia with its outstanding Simien National Park, and Madagascar with its unique flora and fauna.

If the plan for a World Heritage Trust for major cultural monuments materialises, a chain of reserves in Madagascar would be among the first calls on its funds. And these funds, one hopes, would be directly augmented through the international scientific agency, UNESCO, working in the closest cooperation with FAO and the overseas aid programmes of the wealthier countries. 